\title{
ANALISIS KEMAMPUAN KONEKSI MATEMATIS SISWA MTs NEGERI DI BANDUNG BARAT PADA MATERI SEGIEMPAT DAN SEGITIGA
}

\author{
Siti Nuraidah ${ }^{1}$, Fauziah Siti Dewi Sarifah ${ }^{2}$, Marchasan Lexbin Elvi Judah Riajanto ${ }^{3}$, \\ Rippi Maya ${ }^{4}$ \\ 1,2,3,4 IKIP Siliwangi \\ 11aidahtsuki@gmail.com, ${ }^{2}$ ujefauziahds@gmail.com, ${ }^{3}$ lexbin@stkipsiliwangi.ac.id, \\ rrippimaya@gmail.com
}

\begin{abstract}
This research describes students mathematical connection ability in solving mathematical connection problems in a rectangular and triangular material. The research subjects were 30 students of class IX in one of MTs Negeri in West Bandung. Instruments in this research is a matter of test description of the ability of mathematical connection. Based on the result of mathematical connection ability test taken by 6 students from 30 students, that is 2 students with the high test result, 2 students with the medium test result, and 2 students with the low test result. From the research, it was found that: 1) students with high mathematical connection test result can solve the problem with indicator relation with other subjects and relation with daily life. 2) students with moderate test result can complete test question with indicator relationship with another subject. 3) students with low test result cannot solve all problems of mathematical connection ability. Based on the result of this study can be concluded that the mathematical connection ability of the class IX students in one MTs Negeri in West Bandung is still low.
\end{abstract}

Keywords: Mathematical Connection, Rectangular and Triangular

\begin{abstract}
Abstrak
Penelitian ini mendeskripsikan kemampuan koneksi matematis siswa dalam menyelesaikan soal koneksi matematis pada materi segiempat dan segitiga. Subjek penelitiannya adalah 30 orang siswa kelas IX di salah satu MTs Negeri Bandung Barat. Instrumen dalam penelitian ini adalah soal tes uraian kemampuan koneksi matematis. Berdasarkan hasil tes kemampuan koneksi matematis diambil 6 siswa dari 30 siswa, yaitu 2 siswa dengan hasil tes tinggi, 2 siswa dengan hasil tes sedang, dan 2 siswa dengan hasil tes rendah. Dari penelitian yang dilakukan diperoleh bahwa: 1) siswa dengan hasil tes kemampuan koneksi matematis tinggi dapat menyelesaikan soal dengan indikator hubungan dengan mata pelajaran lain dan hubungan dengan kehidupan sehari-hari. 2) Siswa dengan hasil tes sedang dapat menyelesaikan soal tes dengan indikator hubungan dengan mata pelajaran lain. 3) Siswa dengan hasil tes rendah tidak dapat menyelesaikan semua soal kemampuan koneksi matematis. Berdasarkan hasil penelitian ini dapat disimpulkan bahwa kemampuan koneksi matematis siswa kelas IX disalah satu MTs Negeri di Bandung Barat masih rendah.
\end{abstract}

Kata Kunci: Koneksi Matematis, Bangun Datar Segiempat dan Segitiga

How to cite: Nuraidah, S., Sarifah, F. S. D., Riajanto, M. L. E. J., \& Maya, R. (2018). Analisis Kemampuan Koneksi Matematis Siswa MTs Negeri di Bandung Barat pada Materi Segiempat dan Segitiga. JPMI - Jurnal Pembelajaran Matematika Inovatif, 1 (4), 547-558. 


\section{PENDAHULUAN}

Matematika merupakan ilmu dasar yang akan terus berkembang dengan amat pesat baik dari segi materi ataupun terapannya seiring dengan perkembangan pola pikir manusia. Seperti halnya yang dikemukakan (Hendriana \& Sumarmo, 2014) dengan belajar matematika siswa dapat berlatih menggunakan pikirannya secara logis, analisis sistematik, kritis dan kreatif serta memiliki kemampuan bekerjasama dalam menghadapi berbagai masalah. Dengan demikian matamatika terus berkembang seiring dengan berkembangnya zaman. Matematika berperan penting dalam kehidupan sehari-hari, selain itu matematika juga penting dalam perkembangan ilmu pengetahuan den teknologi. Pembentukan pola pikir siswa dapat dilihat dari kemampuan berupa kecakapan yang dimiliki siswa dalam penguasan materi ataupun konsep.

Matematika merupakan ilmu yang sering digunakan dalam kehidupan. Materi dalam matematika saling berkaitan antara suatu materi dengan materi yang lainnya. Oleh karena itu, hal ini tentu memiliki tujuan agar peserta didik mampu berpikir logis, kritis, krestif serta mampu mengaitkan masalah-masalah matematika yang mampu dihadapinya atau dikenal dengan kemampuan koneksi matematik (Sumarmo, Hidayat, Zukarnaen, Hamidah, \& Sariningsih, 2012). Bruner (Ruseffendi, E, 2006) menyatakan bahwa dalam matematika setiap konsep berkaitan dengan konsep yang lainnya, misal dalil dan dalil, antar teori dengan teori, antar topik dengan topik, ataupun antara cabang matematika dengan cabang matematika lainnya.

Keterkaitan konsep serta cara untuk mengaplikasikannya dibutuhkan sebuah koneksi agar setiap konsep dapat terhubung. Dalam hal ini dapat dilihat bahwa kemampuan awal yang hendaknya dimiliki oleh siswa yaitu kemampuan untuk mengaitkan atau mengkomunikasikan suatu konsep dengan matematis yang pada akhirnya kemampuan koneksi matematis menjadi prasyarat siswa agar mampu menguasai kemampuan-kemampuan yang lebih tinggi dari kemampuan koneksi matematis (Hidayat \& Sumarmo, 2013; Muchlis, Komara, Kartiwi, Nurhayati, Hendriana, \& Hidayat, 2018; Rahmi, Nadia, Hasibah, \& Hidayat, 2017; Wahyu, 2014; Zakiah, Saomi, Syara, Hidayat, \& Hendriana, 2018).

Hal ini dapat dilihat dari penelitian yang dilakukan orleh (Danaryanti \& Tanaffasa, 2016) yang meneliti kemampuan kneksi matematis pada kelas VII SMP yang menghasilkan nilai pencapaian rata-rata kemampuan koneksi matematis siswa SMP hanya 63,3\%. Begitu pula penelitian yang dilakukan oleh (Saminanto \& Kartono, 2015) juga menunjukan bahwa ratarata kemampuan koneksi matematis siswa sekolah menengah masih rendah, yaitu berada pada nilai 34\%. Sehingga dapat diabil kesimpulan bahwa kemampuan koneksi matematis siswa disekolah menengah belum mencapai katagori baik.

Berdasarkan uraian diatas, maka perlu dilakukan penelitian pada analisis kemampuan koneksi matematis siswa di salah satu MTs Negeri di Bandung Barat pada materi Segiempat dan Segitiga. Adapunr umusan masalah dari penelitian ini yaitu Bagaimana analisis kemampuan koneksi matematis siswa kelas IX di MTsN di Bandung Barat.

\section{METODE}

Penelitian ini merupakan penelitian deskriptif kualitatif dengan instrumen penelitian berupa soal tes kemampuan koneksi matematika. Penelitian ini dimaksudkan untuk mendeskripsikan tentang kemampuan koneksi matematis siswa kelas IX di salah satu MTs Negeri di Bandung Barat pada subpokok bahasan segiempat dan segitiga. Pada penelitian ini dianalisis 
bagaimana kemampuan koneksi matematika dengan tiga indikator yaitu, mengaitkan konsep antar matematika, hubungan matematika dengan mata pelajaran lain, dan mengaitkan masalah matematika dalam kehidupan sehari-hari. Subjek dalam penelitian ini adalah siswa kelas IX di salah satu MTs Negeri di Bandung Barat yang telah menerima materi segiempat dan segitiga. Sampel diambil berdasarkan hasil tes kemampuan koneksi matematis yang telah diberikan, sesuai skor kemampuan koneksi matematika tinggi, sedang, dan rendah.

Langkah pertama dalam penelitian ini yaitu melakukan kegiatan pendahuluan dengan menentukan tempat penelitian dan jadwal pelaksanaan penelitian. Selanjutnya, menyusun instrumen penelitian. Kemudian sebelum dilakukan pengumpulan data, dilakukan terlebih dahulu validasi instrumen (soal tes kemampuan koneksi matematika). Validasi instrumen dilakukan oleh tiga orang validator yaitu 2 orang dosen pendidikan matematika dan seorang guru mata pelajaran matematika MTs Negeri di Bandung Barat.

Teknik pengumpulan data yang digunakan dalam penelitian ini adalah metode tes. Setelah subjek penelitian terpilih yaitu siswa kelas IX di MTs Negeri di Bandung Barat, selanjutnya subjek penelitian diberi soal tes kemampuan koneksi matematika dan mencari hal-hal yang tidak muncul pada saat tes tersebut, sehingga peneliti dapat mengetahui bagaimana kemampuan koneksi matematika siswa pada subpokok bahasan segiempat dan segitiga. Selanjutnya dilakukan analisis data terhadap data yang telah diperoleh dari tes yang telah dilakukan. Langkah terakhir yaitu membuat kesimpulan terhadap hasil analisis data tersebut.

\section{HASIL DAN PEMBAHASAN}

\section{Hasil}

Hasil tes kemampuan koneksi matematis yang dilakukan di salah satu MTs Negeri di Bandung Barat tersaji dalam tabel dibawah ini:

Tabel 1. Rata-rata hasil tes butir soal koneksi matematis

\begin{tabular}{llcc}
\hline $\begin{array}{l}\text { No } \\
\text { Soal }\end{array}$ & \multicolumn{1}{c}{ Indikator } & $\begin{array}{c}\text { Mean } \\
(\mathrm{SMI}=4)\end{array}$ & Persentase \\
\hline 1. & Memahami hubungan antar topik matematika & 0,73 & $18,06 \%$ \\
2. & Memahami hubungan antar topik matematika & 0,74 & $18,61 \%$ \\
3. & Memahami hubungan matetika dengan mata pelajaran lain & 2,23 & $55,83 \%$ \\
4. & Memahami hubungan matematika dengan mata pelajaran lain & 2,26 & $61,53 \%$ \\
5. & Menerapkan matematika dalam kehidupan sehari-hari & 2,27 & $61.67 \%$ \\
\hline
\end{tabular}

Berdasarkan Tabel 1. di atas yang menunjukan hasil dari rata-rata dan persentase tes setiap butir soal kemampuan koneksi matematis. Berdasarkan indikator yang digunakan, pada soal nomor 1 dan 2 dengan indikator yang sama yaitu memahami hubungan antar topk matematika menunjukan hasil yang sangat rendah. Hasil jawaban dari semua siswa tidak ada yang dapat mengerjakan dengan benar, baik itu dari segi proses/prosedur. Pada soal nomor 3 dan 4 dengan indikator memahami hubungan matematika denagan mata pelajaran lain, memperoleh rata-rata cukup baik. Hal tersebut didapat berdasarkan jawaban siswa, hampir seluruh siswa sudah bisa memahami hubungan topik/prosedur dan mengaitkan dengan mata pelajaran lain tetapi kebanyakan siswa menggunakan prosedur yang kurang tepat. Pada soal nomor 5 dengan indikatormenggunakan matematika dalam kehidupan sehari-hari sudah cukup baik, halini 
dapat dilihat dari jawaban siswa yang hampir seluruhnya hampir benar dalam menjawab soal yang diberikan.

\section{Pembahasan}

Hasil yang diperoleh dari tes kemampuan koeksi matematis yang dikelompokan berdasarkan kategori tinggi sedang dan rendah. Menurut (Maya \& Sumarmo, 2011), hasil tes dikategorikan tinggi jika skornya lebih besar sama dengan 70\%, sedang jika skorna dari 55\% hingga kurang dari 70\%, dan rendah bila skornya kurang dari 55\%. Berikut ini disajikan tabel hasil tes kemampuan koneksi matematis berdasarkan kategori tinggi, sedang dan rendah:

Tabel 2. Hasil tes kemampuan koneksi matematis

\begin{tabular}{|c|c|c|c|c|c|c|c|}
\hline \multicolumn{2}{|c|}{ Kategori } & \multicolumn{5}{|c|}{ Skor Tiap Butir Soal } & \multirow{2}{*}{ Total } \\
\hline & & $\mathrm{X} 1$ & $\mathrm{X} 2$ & $\mathrm{X} 3$ & $\mathrm{X} 4$ & X5 & \\
\hline \multirow{3}{*}{$\begin{array}{l}\text { Tinggi } \\
(\mathrm{N}=3)\end{array}$} & Rata-Rata & 1,33 & 1,00 & 3,33 & 3,33 & 3,67 & 2,53 \\
\hline & Persentase & $33,33 \%$ & $25,00 \%$ & $83,33 \%$ & $83,33 \%$ & $91,67 \%$ & $63,33 \%$ \\
\hline & $\mathrm{S}$ & 0,33 & 1,00 & 1,33 & 0,33 & 0,33 & 0,67 \\
\hline \multirow{3}{*}{$\begin{array}{l}\text { Sedang } \\
(\mathrm{N}=15)\end{array}$} & Rata-Rata & 0,67 & 0,73 & 2,20 & 2,47 & 2,40 & 1,69 \\
\hline & Persentase & $16,67 \%$ & $18,33 \%$ & $55,00 \%$ & $61,67 \%$ & $60,00 \%$ & $42,33 \%$ \\
\hline & $\mathrm{S}$ & 0,38 & 0,27 & 0,52 & 0,45 & 0,42 & 0,41 \\
\hline \multirow{3}{*}{$\begin{array}{l}\text { Rendah } \\
(\mathrm{N}=12)\end{array}$} & Rata-Rata & 0,17 & 0,50 & 1,17 & 1,58 & 1,33 & 0,95 \\
\hline & Persentase & $4,17 \%$ & $12,50 \%$ & $29,17 \%$ & $39,58 \%$ & $33,33 \%$ & $23,75 \%$ \\
\hline & $\mathrm{S}$ & 0,15 & 0,27 & 0,52 & 0,45 & 0,42 & 0,36 \\
\hline \multicolumn{2}{|c|}{ Total Persentase } & $18,06 \%$ & $18,61 \%$ & $55,83 \%$ & $61,53 \%$ & $61,67 \%$ & $43,14 \%$ \\
\hline
\end{tabular}

Berdasarkan Tabel 2. di atas dapat dilihat bahwa siswa yang mengikuti tes berjumlah 30 siswa. Setelah tes kemampuan koneksi diolah diperoleh siswa dengan hasil tes koneksi matematis tinggi berjumlah 3 siswa, siswa dengan hasil tes sedang 15 siswa, dan siswa dengan hasil tes rendah berjumlah 12 siswa. Siswa yang memperoleh hasil tes tinggi memperoleh persentase $63,33 \%$, siswa yang mendapatkan hasil tes sedang dengan memperoleh persentase $42,33 \%$, dan siswa dengan hasil tes rendah dengan persentase $23,75 \%$. Dari hasi ltes tersebut dapat dilihat bahwa siswa yang memiliki hasil tes tinggi belum bisa dikatakan tinggi karena hasilnya tergolong pada kriteria sedang. Begitupun dengan siswa yang memperoleh hasil tes sedang dan rendah belum memenuhi kriteria.

Berdasarkan hasil tes di atas, diambil jawaban 6 siswa yang akan dianalisis untuk mewakili tiap tingkatan dari hasil tes koneksi matematis secara acak, yaitu 2 siswa yang memiliki hasil tes kemampuan koneksi matematika tinggi, 2 siswa yang memperoleh hasil tes kemampuan koneksi matematika sedang, dan 2 siswa dengan hasil tes kemampuan koneksi matematika rendah.

Dari hasil Tabel 1 dan Tabel 2 di atas, baik itu hasil dari rata-rata setiap butir soal ataupun hasil siswa secara keseluruhan masih kurang, untuk itu akan dianalisis untuk setiap indikator 
soal. Dari indikator koneksi matematis yang digunakan akan diwakili oleh 1 soal untuk indikator yang sama. Untuk indikator memahami hubungkan antar topik matematika nomor 1, memahami hubungkan matematika dengan mata pelajaran lain nomor 4 , dan menerapkan matematika dalam kehidupan sehari-hari oleh nomor 5. Berikut hasil analisis dari setiap indikator dengan hasil tes kemampuan koneksi siswa tinggi, sedang dan rendah.

\section{a. Indikator: memahami hubungan antar topik matematika}

Soal : Sebuah persegi yang panjang sisi-sisinya $\mathrm{s} \mathrm{cm}$. Kemudian persegi serupa diletakan berimpit disebelah kanan persegi sebelumnya. Proses tersebut dilanjutkan sampai persegi ke n. Gambarlah situasi tersebut! Kemudian buatlah model matematika untuk menentukan keliling persegi panjang!

1) Siswa dengan hasil kemampuan koneksi tinggi

Berikut ini jawaban no 1 dari siswa A dengan no urut 10 dan siswa B dengan no urut 17.

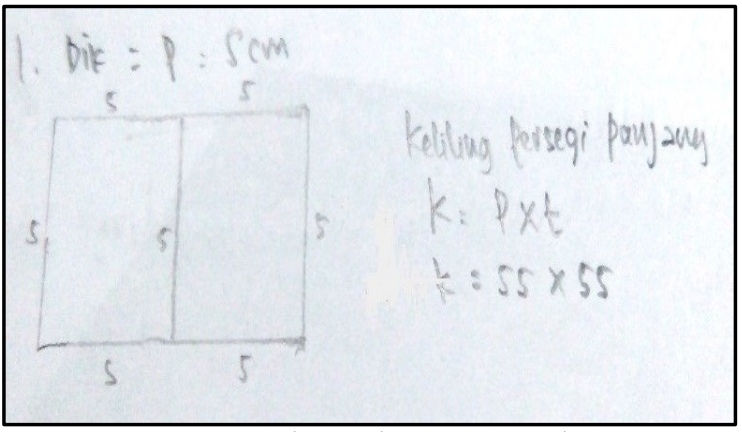

Gambar 1. Jawaban siswa A soal nomor 1

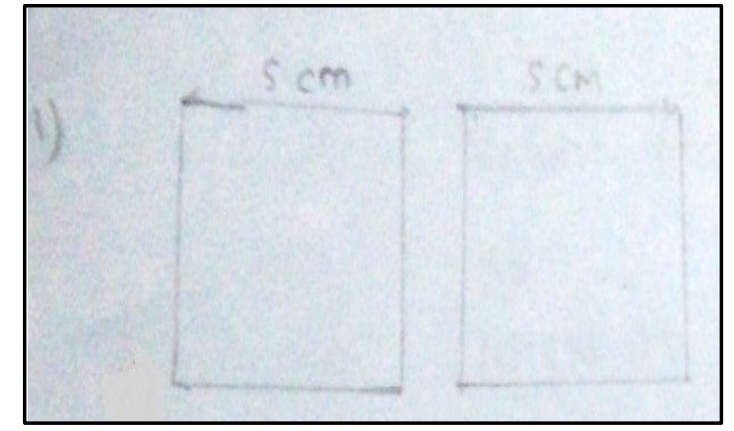

Gambar 2. Jawaban siswa B soal nomor 1

Dari gambar 1 dan 2 dianalisis kesalan jawaban, siswa A tidak menuliskan proses yang termuat dalam menemukan jawaban selain itu siswa juga tidak dapat mengidentifikasi prosedur/proses yang bersangkutan dalam soal. Siswa juga kurang tepat dalam menginfertasikan $\mathrm{s} \mathrm{cm}$ menjadi $5 \mathrm{~cm}$. Jawaban dari siswa B tidak akurat, siswa B hanya menggambarkan saja. Serta dalam menyelesaikan soal siswa belum mampu hubungan proses/prosedut yang terdapat dalam soal.

2) Siswa dengan hasil kemampuan koneksi sedang

Berikut ini adalah jawaban nomor 1 dari siswa $\mathrm{C}$ dengan nomor urut 3 dan siswa $\mathrm{D}$ dengan nomor urut 21.

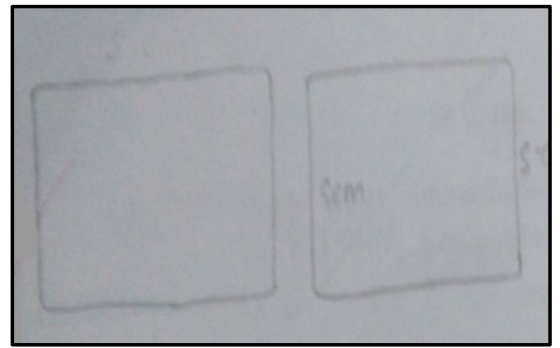

Gambar 3. Jawaban siswa C soal nomor 1

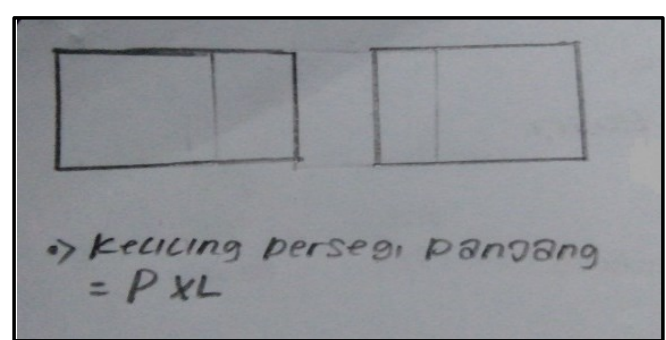

Gambar 4. Jawaban Siswa D soal nomor 1

Dari gambar 3 dan 4, untuk jawaban yang diberikan siswa $\mathrm{C}$ tidak akurat, siswa $\mathrm{C}$ hanya menggambar saja. Dan dari jawaban siswa D hampir sama seperti siswa $\mathrm{C}$ hanya 
menggambarkan saja bentuk dari persegi yang akan dibuat menjadi persegi panjang. Serta siswa D keliru dalam menuliskan rumus persegipanjang untuk keliling atau untuk luas.

3) Siswa dengan hasil kemampuan koneksi rendah

Berikut ini jawaban siswa $\mathrm{E}$ dengan no urut 8 dan $\mathrm{F}$ dengan no urut 19 dalam menyelesaikan soal nomor 1.

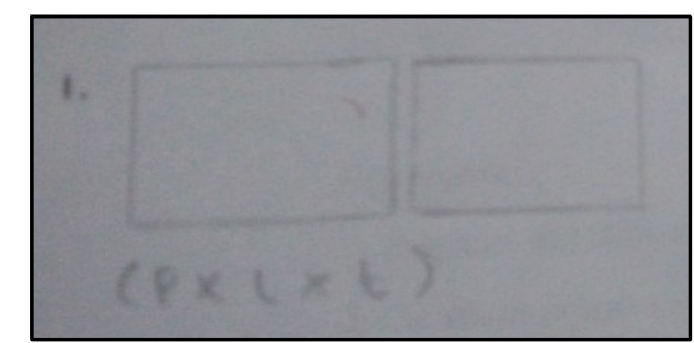

Gambar 5. Jawaban siswa E soal nomor 1

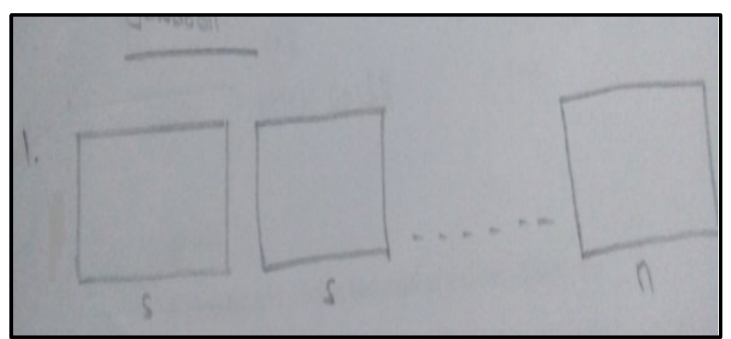

Gambar 6. Jawaban siswa F soal nomor 1

Dari gambar 5 dan 6 dianalisis jawaban siswa E dan F. Siswa E belum mampu mengidentifikasi konsep dalam soal serta belum mampu mengidentifikasi hubungan tang termuat dala soal. Begitupun dengan jawaban dari siswa $F$ sama seperti jawaban yang diberikan siswa E.

Berdasarkan uraian diatas terdapat beberapa kesalahan siswa dalam menyelesaikan soal. Dengan indikator yang diukur, seharusnya siswa mengidentifikasi terlebih dahulu konsep yang terdapat dalam soal, kemudian mengidentifikasi hubungan proses/prosedur. Dari jawaban yang diberikan siswa belum memenuhi kriteria, baik itu dari yang tertera pada gambar maupun yang tidak, hampir semua siswa melakukan hal yang sama yaitu hanya menggambarkan saja dan salah dalam menuliskan $\mathrm{s} \mathrm{cm}$ menjadi $5 \mathrm{~cm}$, serta keliru dalam penuliskan rumus untuk keliling persegi panjang dan rumus untuk luas persegi panjang. Dari hal tersebut kemampuan koneksi matematis dengan indikator memahami hubungan antar topik dalam matematika belum tercapai.

\section{b. Indikator : memahami hubungan matematika dengan mata pelaaran lain}

Soal : Raisa bermain sepeda mengelilingi taman berbentuk segitiga dengan sisi-sisinya 90m, $70 \mathrm{~m}$, dan $120 \mathrm{~m}$. Setiap 2 menit raisa dapat menempuh jarak $112 \mathrm{~m}$. Buatlah model mateatika untuk menentukan waktu yang dibutuhkan raisauntuk mengelilingi lapangan sebanyak dua kali putaran?

1) Siswa dengan hasil kemampuan koneksi tinggi 


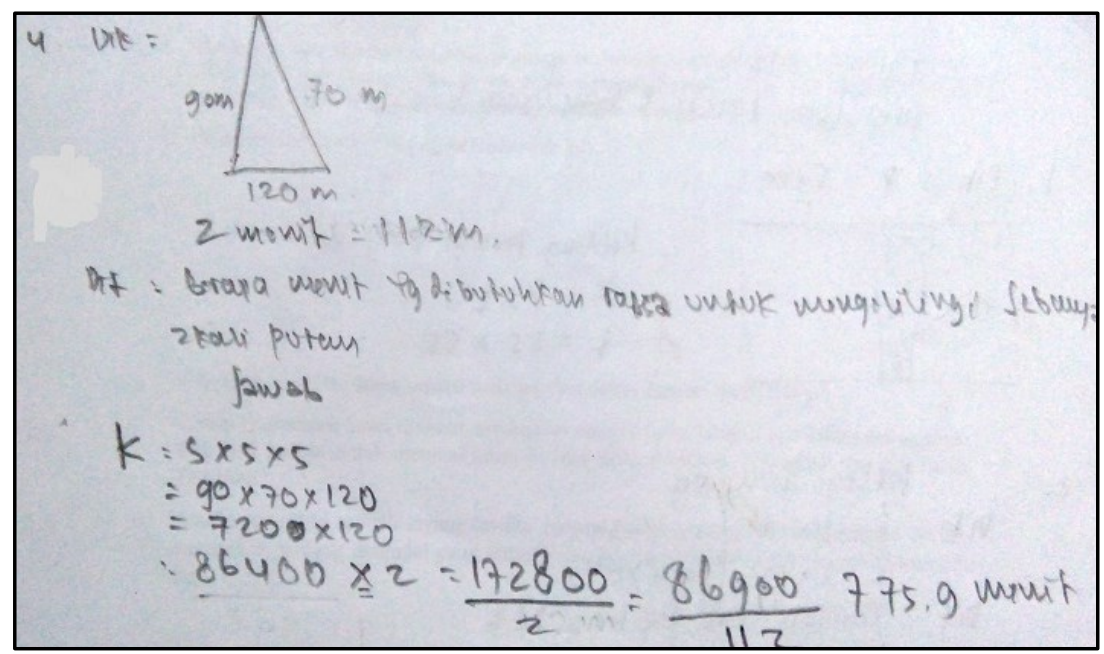

Gambar 7. Jawaban siswa A soal nomor 4

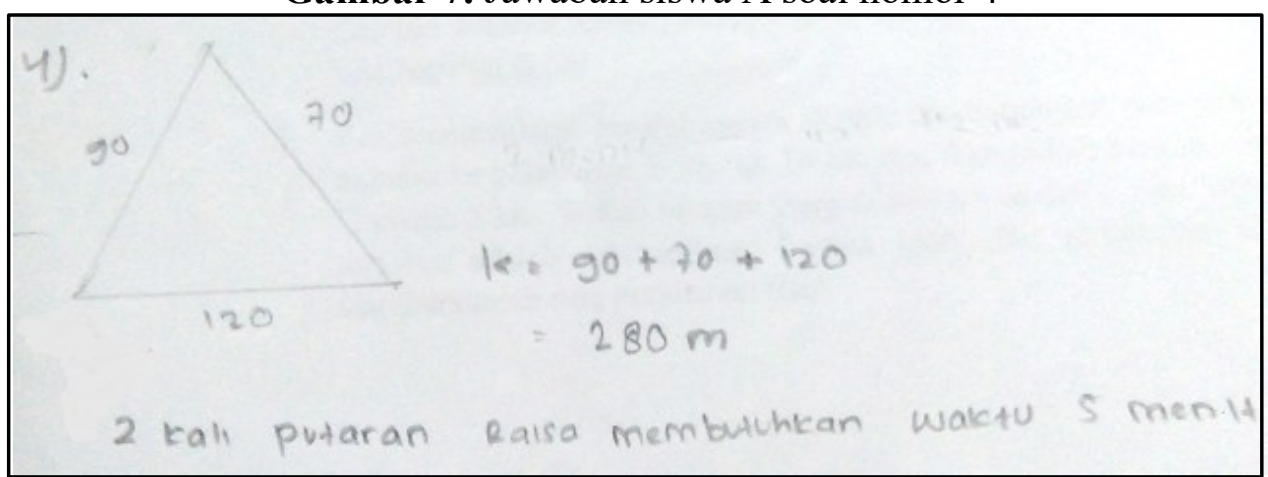

Gambar 8. Jawaban siswa B soal nomor 4

Dari gambar 7 dan 8 dianalisis jawaban siswa, untuk siswa A sudah dapat mengidentifikasi soal. Konsep yang digunakan kurang tepat dan siswa belum mampu menghubungkannya dengan konsep lain diluar matematika. Untuk siswa B tidak mengidentifikasi konsep yang termuat dalam soal dan siswa tidak menjelaskan konsep ang dia gunakan dalam menyelesaikan masalah, walaupun pada tahap awal rumus yang digunakan oleh siswa sudah tepat (untuk keliling segitiga).

2) Siswa dengan hasil kemampuan koneksi sedang

Berikut ini jawaban siswa $\mathrm{C}$ dengan no urut 3 dan siswa $\mathrm{D}$ dengan no urut 21 untuk soal nomor 4.

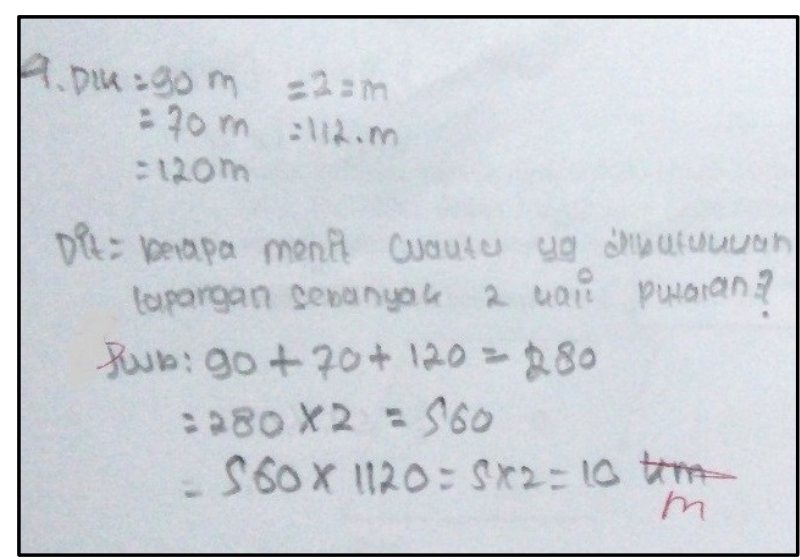

Gambar 9. Jawaban siswa C soal nomor 4

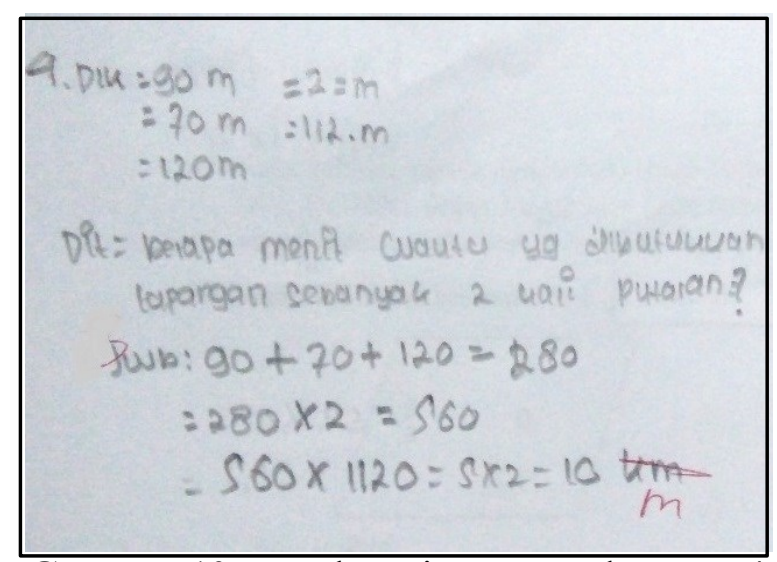

Gambar 10. Jawaban siswa D soal nomor 4 
Dari gambar 7 dan 8 dianalisis jawaban siswa, siswa $\mathrm{C}$ sudah mampu mengidentifikasi konsep dalam soal, jawaban siswa benar tetapi kurang tepat dalam menentukan satuan panjang. Konsep yang digunakan siswa benar tetapi Siswa tidak menyebutkan konsep apa yang dia gunakan untuk menyelesaikan soal yang bersangkutan. Siswa D sudah mangidentifikasi soal, jawabanyang diberikan hampir benar karena penyelesaiannya belumtuntas. Konsep yang digunakan siswa benar tetapi siswa tidak menuliskan konsep apa yang digunakan untuk menyelesaikan soal.

3) Siswa dengan hasil kemampuan koneksi rendah

Berikut ini jawaban siswa $\mathrm{E}$ dengan no urut 8 dan diswa $\mathrm{F}$ dengan no urut 19 untuk soal nomor 4

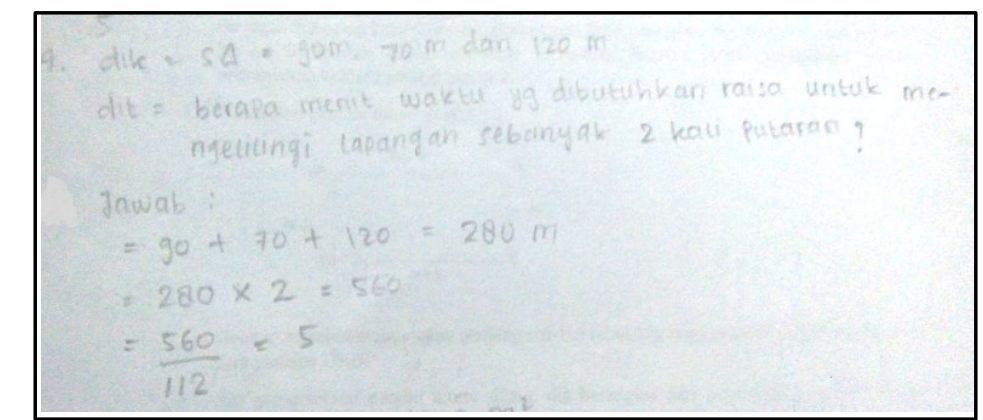

Gambar 11. Jawaban siswa E soal nomor 4

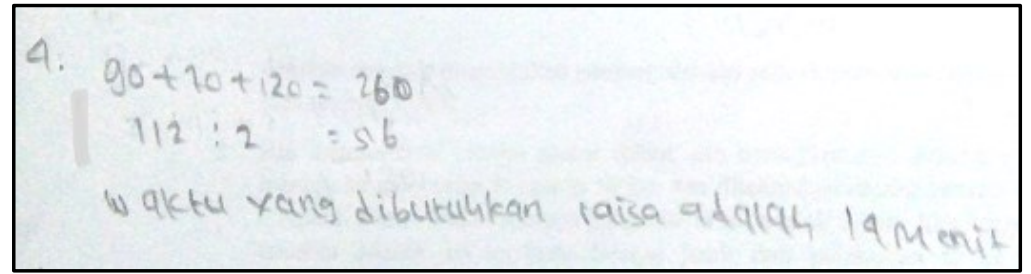

Gambar 12. Jawaban siswa F soal nomor 4

Dari gambar diatas dianalisis jawaban siswa untuk soal nomor 4. Siswa E dapat mengidentifikasi soal. Konsep awal yang digunakan siswa sudah benar, tetapi siswa tidak menuliskan konsep apa yang dia gunakan. Serta jawaban siswa belum sepenuhnya selesai. Siswa F tidak mengidentifikasi soal serta konsep dan prosedur yang digunakan. Serta belum mampu untuk mengaitkan konsep matematika dengan konsep diluar matematika.

Berdasarkan uraian diatas dari analisis jawaban semua siswa untuk soal no 4 semua siswa sudah benar dalam menghitung keliling segitiga akan tetapi untuk menentukan waktu yang dibutuhkan untuk mengelilingi lapangan pada soal, hanya sebagian siswa yang dapat menyelesaikan sampai tahap itu dan mendapatkan jawaban yang benar. Pada indikator kemampuan koneksi matematis memahami hubungan matematika dengan matapelajaran lain sudah cukup baik tetapi belum sepenuhnya tercapai.

\section{c. Indikator : menggunakan matematika dalam kehidupan sehari-hari}

Soal : Perhatikan sketsa kebun pak budi dibawah ini!

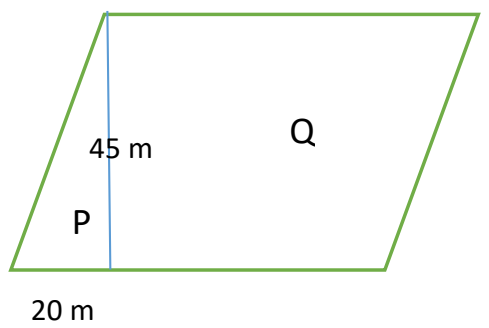


Pak Budi memiliki lahan seperti pada gambar diatas dengan luas $1200 \mathrm{~m}^{2}$. Lahan Q ditanami umbi-umbian, sedangkan sisanya yaitu lahan $\mathrm{P}$ tidak ditanami apapun. Pak budi berniat untuk menjual lahan P. Jika lahan P terjual, berapakah sisa luas lahan Pak Budi

1) Siswa dengan hasil kemampuan koneksi tinggi

Berikut ini jawaban nomor 5 dari siswa A dengan nomor urut 10 dan siswa $\mathrm{B}$ dengan nomor urut 17.

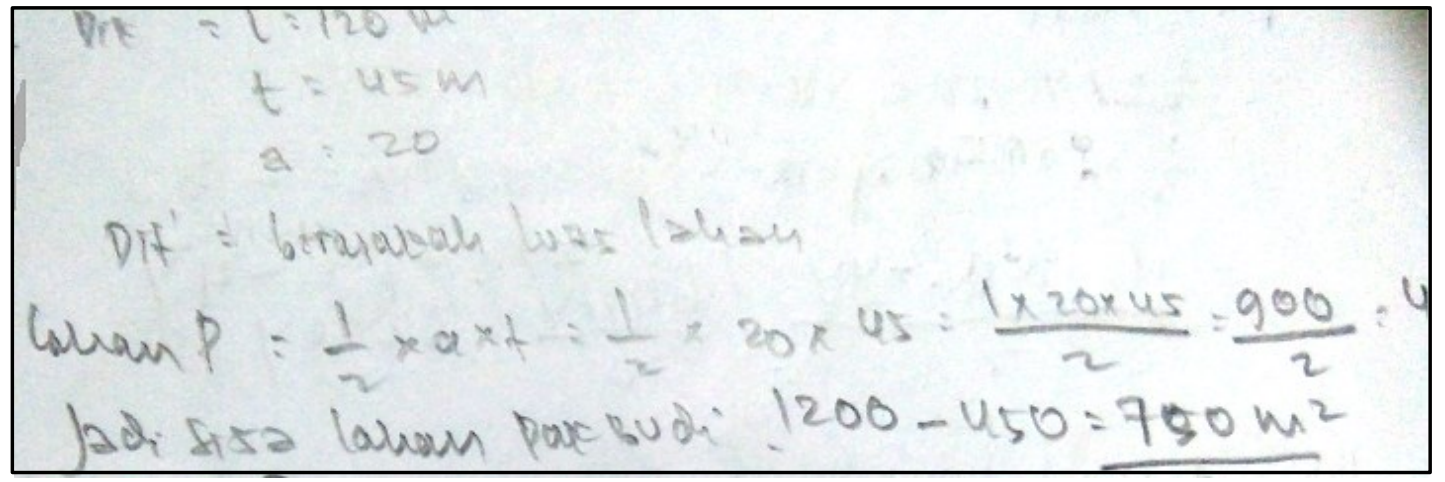

Gambar 13. Jawaban siswa soal nomor 5

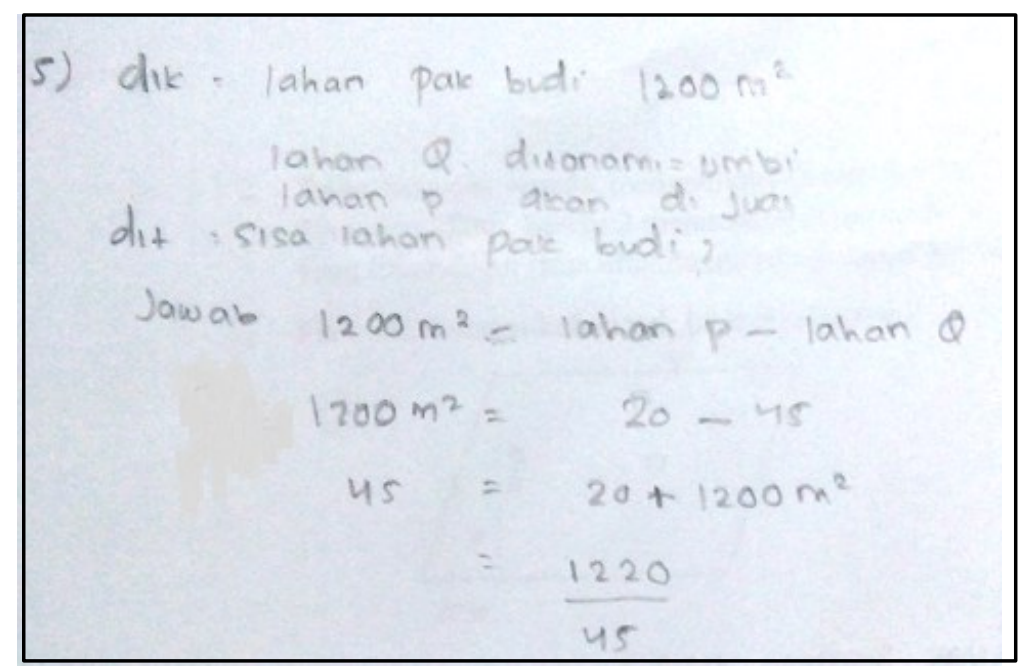

Gambar 14. jawaban siswa B soal nomor 5

Berdasarkan gambar 13 dan 14 dari jawaban siswa A dan B dianalisis. Siswa A sudah mampu mengidentifikasi konsep/prosedur yang termuat dalam soal, konsep yang digunakan siswa benar sehingga jawaban siswa benar. Maka siswa dapat menghubungkan masalah matematika dengan kehidupan sehari-hari. Siswa B sudah mampu mengidentifikasi soal, tetapi konsep dan prosedur yang disw gunakan kurang tepat.sehingga jawaban siswapun salah.

2) Siswa dengan hasil kemampuan koneksi sedang

Berikut ini jawaban dari siswa $\mathrm{C}$ dengan nomor urut 3 dan siswa $\mathrm{D}$ dengan nomor urut 21 untuk soal nomoe 5 


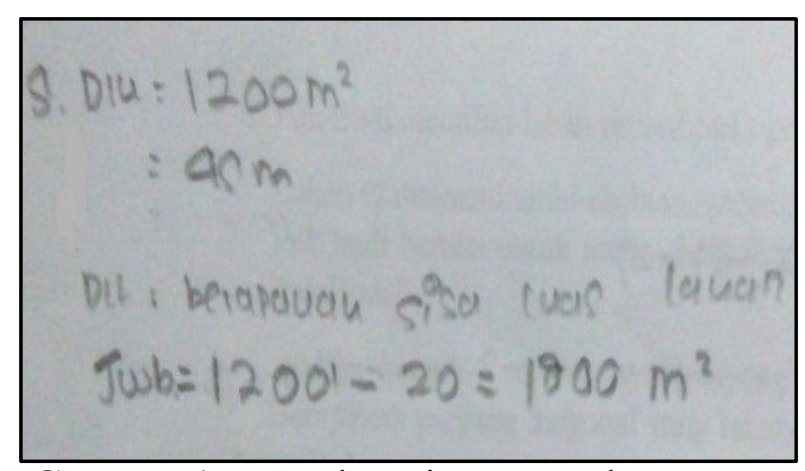

Gambar 15. Jawaban siswa C soal nomor 5

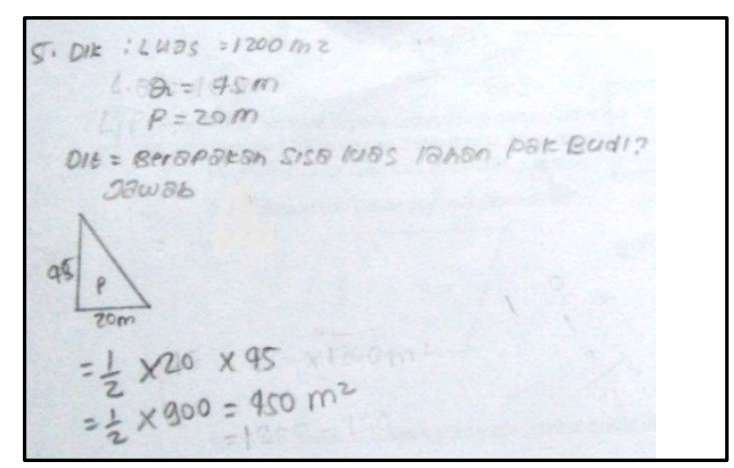

Gambar 16. Jawaban siswa D soal nomor 5

Berdasarkan gambar diatas, dianalisis hasil jawaban siswa C dan D. Siswa C, tidak mengidentifikasi konsep/prosedur yang termuat dalam soal, tidak menuliskan konsep yang dia gunakan, sehingga jawaban siswapun salah. Siswa D, siswa sudah mengidentifikasi masalah yang terdapat dalam soal, konsep pertama yang digunakan siswa betul tetapi siswa tidak menyelesaikannya sampai akhir, sehingga jawaban siswapun kurang tepat.

3) Siswa dengan hasil kemampuan koneksi rendah

Berikut ini jawaban siswa E dengan nomor urut 8 dan siswa F dengan nomor urut 19 untuk soal nomor 5.

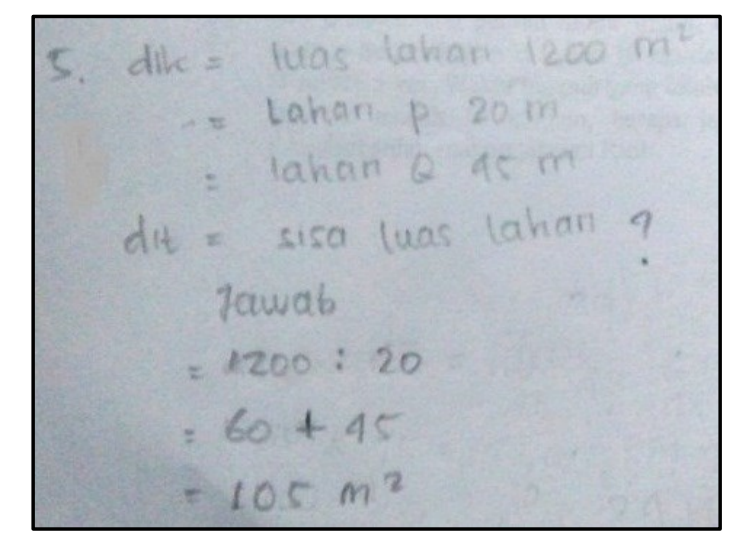

Gambar 17. Jawaban siswa E soal nomor 5

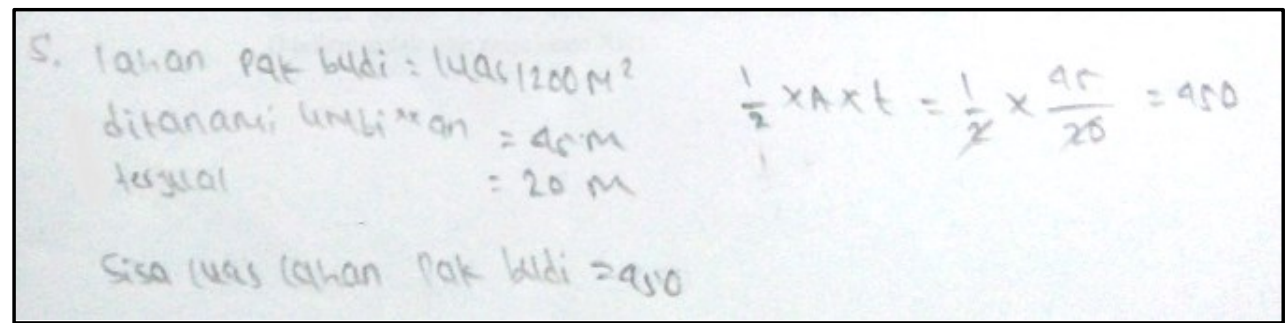

Gambar 18. Jawaban siswa F soal nomor 5

Berdasarkan gambar diatas dianalisis jawaban siswa E dan F. Siswa E tidak mengidentifikasi proses/prosedur yang termuat dalam soal, rumus yang digunakan salah sehingga jawaban siswa salah. Serta siswa juga tidak menjelaska hubungan antar luas jajargenjang gengan lahan lahan yang dimiliki pak Budi. Siswa F, siswa kurang tepat dalam mengidentifikasi proses/prosedur, prosedur pertama (luas segitiga benar) tetapi siswa tidak melanjutkan ke prosedur berikutnya dan langsung membuat kesimpulan, sehingga jawaban siswa pun salah. 
Berdasakan uraian diatas, dari analisis jawaban siswa dengan hasil tes tinggi sedang sudah dapat mengerjakan soal dengan baik walaupun ada beberapa siswa yang keliru dalam menghitungnya. Jawaban yang diberikan siswa dengan hasil tes rendah belum memenuhi kriteria jawaban dan terdapat kesalahan-kesalahan yang dilakukan. Jawaban yang diberikan belum memenuhi indikator yang diukur, sehingga untuk indikator kemampuan koneksi menggunakan matematika dalam kehidupan sehari-hari cukup baik akan tetapi perlu ditingkatkan lagi. Hal ini bisa disebabkan oleh beberapa hal seperti, karena siswa lupa dengan materi, ataupun pembelajaran matematika yang digunakan belum sesuai. Meskipun demikian, (Lexbin, 2014) wajar bila pembelajaran matematika belum memberikan dampak positif, yang antara lain menghantar siswa pada kepemilikan kemampuan matematis.

\section{KESIMPULAN}

Berdasarkan hasil dan pembahasan diatas maka dapat diambil kesimpulan untuk kemampuan koneksi matematis siswa di salah satu MTsN di Bandung Barat masih rendah. Dimana siswa dengan hasil tes kemampuan koneksi matematis tinggi dapat menyelesaikan soal dengan indikator hubungan dengan mata pelajaran lain dan hubungan dengan kehidupan sehari-hari. Siswa dengan hasil tes sedang dapat menyelesaikan soal tes dengan indikator hubungan dengan mata pelajaran lain. Siswa dengan hasil tes rendah tidak dapat menyelesaikan semua soal kemampuan koneksi matematis.

\section{UCAPAN TERIMA KASIH}

Pada kesempatan kali ini penulis mengucapkan banyak terimakasih dan memberikan penghargaan yang setinggi-tingginya kepada berbagai pihak yang telah banyak membantu dan mendukung dalam pembuatan artikel ini.

\section{DAFTAR PUSTAKA}

Danaryanti, A., \& Tanaffasa, D. (2016). Penerapan Model Problem Prompting Learning Untuk Meningkatkan Kemampuan Koneksi Matematis Siswa SMP. Page 1 EDU-MAT Jurnal Pendidikan Matematika, Volume 4.

Hendriana, H., \& Sumarmo, U. (2014). penilaian pembelajaran matematika.

Hidayat, W., \& Sumarmo, U. (2013). Kemampuan Komunikasi dan Berpikir Logis Matematika serta Kemandirian Belajar. dalam Jurnal Delta-fi, 2(1).

Lexbin, M. (2014). Pengembangan pembelajaran era post modern menuju ketercapaian kemampuan matematis siswa. Infinity Jurnal, 3(1), 81-100.

Maya, R., \& Sumarmo, U. (2011). Mathematical Understanding and Proving Abilities: Experiment With. Journal On Mathematics Education (Indo MS-JME), 2(2), 231-250.

Muchlis, A., Komara, E. S., Kartiwi, W., Nurhayati, N., Hendriana, H., \& Hidayat, W. (2018). MENINGKATKAN KONEKSI MATEMATIS SISWA SMP MELALUI PENDEKATAN OPEN-ENDED DENGAN SETTING KOOPERATIF TIPE NHT. KALAMATIKA Jurnal Pendidikan Matematika, 3(1), 81-92. 
558 Nuraidah, Sarifah, Riajanto \& Maya, Analisis kemampuan koneksi matematis siswa ...

Rahmi, S., Nadia, R., Hasibah, B., \& Hidayat, W. (2017). The Relation between Self-Efficacy toward Math with the Math Communication Competence. Infinity Journal, 6(2), 177182.

Ruseffendi, E, T. (2006). Pengantar kepada Membantu Guru Mengembangkan Kompetensinya dalam Pengajaran Matematika untuk Meningkatkan CBSA. Bandung: Tarsito.

Saminanto, \& Kartono. (2015). Analysis of mathematical connection ability in linear equation with one variable based on connectivity theory. International Journal of Education and Research, 3(4), 259-270.

Sumarmo, U., Hidayat, W., Zukarnaen, R., Hamidah, M., \& Sariningsih, R. (2012). Kemampuan dan Disposisi Berpikir Logis, Kritis, dan Kreatif Matematik (Eksperimen terhadap Siswa SMA Menggunakan Pembelajaran Berbasis Masalah dan Strategi ThinkTalk-Write). Jurnal Pengajaran MIPA, 17(1), 17-33.

Wahyu, H. (2014). THE IMPLEMENTATION OF MEAs INSTRUCTION TO STUDENTS'MATHEMATICS PROBLEM SOLVING AND CONNECTING ABILITY. In Proceeding of International Conference On Research, Implementation And Education Of Mathematics And Sciences 2014. Yogyakarta State University.

Zakiah, L., Saomi, A. S. N., Syara, R., Hidayat, W., \& Hendriana, H. (2018). THE EFFICIENCY OF USING EDUCATION VIDEOS ON THE LINEAR PROGRAM MATERIAL AS OBSERVED IN VOCATIONAL HIGH SCHOOL STUDENTS'MATHEMATICAL COMMUNICATION ABILITY. Journal Of Educational Experts (JEE), 1(1), 11-18. 